\title{
DESIGN APPROACHES FOR CLT CONNECTIONS
}

\section{Mohammad Mohammad*}

Senior Research Advisor

Natural Resources Canada

Ottawa, Ontario, Canada K1A 0E4

E-mail: mohammad.mohammad@ canada.ca

\section{Hans J. Blaß}

Professor

Karlsruhe Institute of Technology

Karlsruhe 76297, Germany

E-mail: hans.blass@kit.edu

\section{Alexander Salenikovich}

Professor

Université Laval

Quebec, Quebec, Canada G1V 0A6

E-mail: alexander.salenikovich@sbf.ulaval.ca

\section{Andreas Ringhofer}

Research Associate

Institute of Timber Engineering and Wood Technology

Graz University of Technology

Graz 8010, Austria

E-mail: andreas.ringhofer@tugraz.at

\section{Philip Line}

Director, Structural Engineering American Wood Council

Leesburg, VA 20175

E-mail: pline@awc.org

\section{Douglas Rammer}

Research General Engineer USDA Forest

Madison, WI 53726

E-mail: drammer@fs.fed.us

\section{Tobias Smith}

General Manager

PTL Structural Consultants

Christchurch, New Zealand

E-mail: t.smith@ptlnz.com

\section{Minghao Li}

Senior Lecturer

University of Canterbury

Christchurch, New Zealand

E-mail: minghao.li@canterbury.ac.nz

(Received August 2017)

* Corresponding author 


\begin{abstract}
Various design approaches for establishing the resistance of connections in cross-laminated timber (CLT) structures have been developed and adopted in timber design standards worldwide. Although the fundamental principles are similar, the new design provisions for CLT connections have been aligned in some standards with the existing design philosophy and format adopted for sawn timber and glulam using traditional fasteners such as dowels, nails, and wood screws for consistency and simplicity, in the other standards, alternate approaches have been developed. This article presents a snap shot of the various design approaches for connections in CLT adopted in Europe, Canada, the United States, and New Zealand. The intent is for the reader to have a better knowledge of the underpinning assumptions, principles, and the adopted design rules in each of these standards.
\end{abstract}

Keywords: CLT, connections design, Eurocode 5, CSA O86, NDS, NZ 3603, embedment, withdrawal.

\section{INTRODUCTION}

Cross-laminated timber (CLT) panels are usually made by cross-lamination of graded lumber using either structural adhesives or wooden or metal dowels. The cross-lamination and the built-up nature of the panel, together with unique features, including edge joints, stress-relieving grooves, and gaps between laminations, complicate the determination of the lateral and withdrawal resistance of fastenings in CLT compared with traditional sawn timber, glulam, or structural composite lumber. CLT panels from some manufacturers are produced with up to 6$\mathrm{mm}$ gaps between the laminations (Uibel and Blaß 2006).

It is well established and recognized in timber design standards that the loading direction relative to the grain orientation of wood affects the lateral load resistance of dowel-type fasteners, such as bolts, lag screws, and self-tapping screws (STS) with diameters greater than $6 \mathrm{~mm}$, in particular, their embedment (or dowel bearing) strength. The embedment strength of smaller fasteners, such as nails and wood screws, is less sensitive to the wood grain orientation. CLT manufacturers in Europe, North America, New Zealand, and elsewhere are aware of the fastening issues, and rigorous testing programs have been established to develop the fastening capacity in their products for different dowel-type fasteners. One of the dominant approaches has targeted the development of the embedment strength formulae specific to CLT, taking into account the type of lamination, layup, wood species, edge joints, and other panel features. Similarly, the withdrawal resistance of fasteners such as screws and nails from the face and edge of the CLT panel has been studied.

Although yielding failure modes in accordance with the European Yield Model (EYM) are dominant for slender fasteners in CLT, there is also a potential for developing brittle failure modes such as row shear, group tear-out, net tension or splitting. However, it is unlikely that such brittle failure modes would govern when fasteners are driven perpendicular to the plane of the panel at appropriate end and edge distances and fastener spacing because of the reinforcing effect of cross-lamination. But when fasteners are driven in the edge of a thin panel or lamination and loaded perpendicular to the plane of the panel, it is possible to trigger splitting because of tensile stress perpendicular to the grain. Therefore, the conditions where brittle failure modes may occur with large diameter fasteners used with CLT have been studied as well. According to tests conducted by Uibel and Blaß (2006) in Europe with dowels and screws loaded perpendicular to the plane of the panel, the connections exhibited considerable ductility. Even when plug shear or splitting occurred in the outer layers, the load remained at the same level or showed a localized marginal drop. Similar results were obtained by Mohammad et al (2014) when testing CLT connections with relatively large diameter bolts in the direction parallel or perpendicular to the grain of the outer lamination.

Various design approaches for establishing the resistance of connections in CLT structures have been developed and adopted in timber design standards worldwide. Although the fundamental principles are pretty much similar, the new design 
provisions for CLT connections have been aligned in some standards with the existing design philosophy adopted for sawn timber and glulam using traditional fasteners such as dowels, nails, and wood screws for consistency and simplicity, and in the other standards, alternate approaches have been developed. This article presents a snapshot of the various design approaches for connections in CLT adopted in Europe (Eurocode 5), Canada (CSA O86), United States (NDS 2105), and New Zealand (NZ 3603). The intent is for the reader to have a better knowledge of the underpinning assumptions and principles and the adopted design rules in each of these standards.

\section{CLT CONNECTIONS IN EUROCODE 5}

\section{European Standardization for Timber Engineered Structures}

The erection of building constructions in the member states of the European Union (EU) is subject to a sequence of material, design, and execution standards. For engineered timber structures, the EN 1995 (or Eurocode 5) series, consisting of Part 1-1: General-Common rules and rules for buildings, Part 1-2: GeneralStructural fire design, and Part 2: Bridges (CEN 2004a,b,c), represents the related European design standard and, thus, the core document of this so-called standardization chain (Toratti 2016). After a long period of development starting in the early 1980s (Kleinhenz et al 2016), the first (and still valid) generation of Eurocode 5 was published by the European Committee for Standardization (CEN) in 2004. In addition to this harmonized, pan-European document setting, "National Annexes" (NAs), published by each national standardization body, serve as national supplements and enable the heterogeneous interpretation of specific content of Eurocode 5 by the member states. This concerns the built environment's safety, nationally adjusted by so-called "Nationally Determined Parameters" (NDP), which are-together with additional, "Non-Contradictory Information" (NCI) - content of the aforementioned NAs. Thus, engineers have to consider up to six design documents (three harmonized and three national ones) when realizing a timber structure in a member state of the EU.

Starting in 2015 and as part of the whole Eurocode series, the first generation of Eurocode 5 is currently under revision. This process-organized by CEN TC 250 (and its subcommittee SC 5) and supported by COST Action FP1402-shall end with the publication of the second Eurocode 5-generation in 2020; a comprehensive summary regarding this ongoing process is given in Kleinhenz et al (2016).

\section{Design Rules for Connections in Eurocode 5}

Restricting the scope to the design of timber connections composed by a certain number of dowel-type single fasteners (note: fasteners deviating from this definition such as punched metal plate fasteners, split ring, shear plate, or toothedplate connectors are excluded from the discussion, this also concerns glued-in systems), corresponding rules are given in Part 1-1, section 8 of EN 1995. Apart from other failure scenarios especially related to the timber member (the area surrounding the connection, the net crosssection, etc.); such a connection's bearing resistance $F_{\text {ef,Rk }}$ can be determined as follows:

$$
F_{\mathrm{ef}, \mathrm{Rk}}=n_{\mathrm{ef}} \cdot F_{\mathrm{Rk}}(\mathrm{N})
$$

Depending on the direction between the load and fastener axis, $F_{\mathrm{Rk}}$ is either the axial 1) or the lateral 2) single fastener's resistance and $n_{\mathrm{ef}}$ the effective number of fasteners which is influenced by the timber's grain direction. In case of 1), the focus is on fasteners, which can be anchored in the timber member (nails, staples, and screws) and reasonably applied for axial loading. The failure scenario for determining $F_{\mathrm{Rk}}$, which depends on the specific timber product, is their withdrawal. The related material property is denoted as characteristic (5\%) withdrawal strength $f_{\mathrm{ax}, \mathrm{k}}$ (or capacity $F_{\mathrm{ax}, \mathrm{Rk}}$ ) and either determined by empirical approaches (smooth nails and screws) or by tests (nails, profiled nails, staples, screws). In case of 2), $F_{\mathrm{Rk}}$ of all dowel-type fasteners covered in Eurocode 5 is 
determined using the EYM, based on Johansen (1949). Here, the fastener's characteristic embedment strength $f_{\mathrm{h}, \mathrm{k}}$ serves as timber-dependent property and - similar to the withdrawal strengthis proposed being determined by different empirical approaches for the different fastener types. To conclude: when restricting the scope to those scenarios for axial and lateral loading, where failure occurs by exceeding $F_{\text {ef,Rk}}$, Eurocode 5 defines two material properties, namely the withdrawal and embedment strength, which depend on the applied timber product and are, thus, focused on within further discussions. Furthermore, comments regarding $n_{\text {ef }}$ and fastener arrangement are given as they also depend on the timber product.

\section{Design of CLT Connections in Eurocode 5}

In fact, the definition (or even the phrase) "CLT" is missing in this first generation of Eurocode 5, Part 1-1. Consequently, the aforementioned design provisions for dowel-type connections in section 8 do not cover the influence of the specific CLT layup on both, the timber-dependent material properties $f_{\mathrm{ax}, \mathrm{k}}\left(F_{\mathrm{ax}, \mathrm{Rk}}\right)$ and $f_{\mathrm{h}, \mathrm{k}}$, and the effective number of fasteners, $n_{\mathrm{ef}}$, and their arrangement, the latter commonly defined by minimum spacing, edge and end distances. It is worth mentioning that this lack of knowledge will be rectified by the ongoing revision process of Eurocode 5. As explained by Kleinhenz et al (2016), new topics not treated so far in the code (not only CLT but also timber-concrete composites) are currently being implemented. Within a next step, already existing sections-here especially section 8 ("Connections") —are adapted to cover characteristics of these new products and building techniques.

In the meantime, a design of CLT connections embedded in Eurocode 5 is only possible by the national adjustments as content of the member states' NAs. This unfortunately causes nationdependent, heterogeneous regulations, whose quality mainly depends on the national timber community's state-of-knowledge. Germany and Austria, for instance, already have long-term experience in manufacturing and applying CLT for structural purposes and accordingly cover design provisions for CLT in their National Annexes to Eurocode 5, Part 1-1.

In the currently valid German National Annex, the DIN EN 1995-1-1/NA (DIN 2013), related NDPs (partial factor $\gamma_{\mathrm{M}}$, modification factors $k_{\mathrm{mod}}$, deformation factors $k_{\mathrm{def}}$, etc.) regarding the application of CLT as building product are provided, whereas any NCI comprising the design of CLT connections is missing. As an alternative, DIN EN 1995-1-1/NA refers to German National Technical Approvals (NTAs) of CLT manufacturers wherein related specifications can be found, c.f. Z-9.1-482 (2015) for instance. By contrast, ÖNORM B 1995 1-1 (ASI 2015) as the Austrian National Annex to Eurocode 5, Part 1-1 includes NDPs regulating the main design parameters of CLT and NCI provides provisions as to how to design connections in CLT. Both, NDPs, and NCI, are provided in Annex K of ÖNORM B 1995-1-1. The regulations for CLT connections given therein shall supplement those of section 8 (which means that existing formulae were not modified) and predominately based on the research work performed by Uibel and Blaß $(2006,2007,2013)$ as it is discussed in the following section. It should be noted, however, that the research by Uibel and Blaß used thinner CLT laminations compared with the common commercial production in Europe and North America. Worth mentioning, their results regarding $f_{\mathrm{h}, \mathrm{k}}$ and $f_{\mathrm{ax}, \mathrm{k}}\left(\right.$ or $F_{\mathrm{ax}, \mathrm{Rk}}$ ) are derived from empirical regression functions based on a comprehensive experimental campaign comprising embedment tests of dowels, nails, and STS, as well as withdrawal tests of nails and screws, conducted in the faces and edges of CLT panels with varying layups ( $N=\{3,5,7\}$ layers) and gap configurations. For a better understanding, Fig 1 illustrates a general definition regarding the specific layup of CLT.

\section{Lateral Resistance of CLT Connections}

Bolts and dowels. Uibel and Blaß (2006) provide two approaches for determining the embedment strength of laterally loaded dowels, installed 


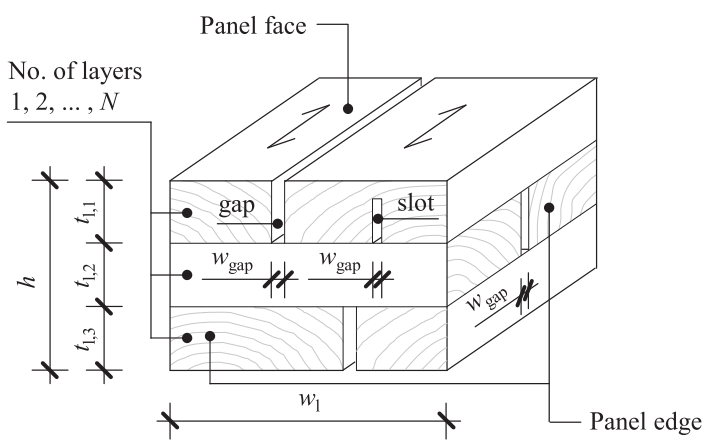

Figure 1. General definition of the specific layup of crosslaminated timber (adapted from Ringhofer 2017).

in the face of CLT panels. Both were derived by means of nonlinear regression analysis of altogether 438 test results and differ in the way the given CLT layup ( $N$ and $t_{1}$ in Fig 1 ) is considered. The first and comparatively simple approach presented in Eqs 2 and 3 has a structure like the common embedment strength model for bolts and dowels, as given in EN 1995-1-1, section 8 (note: here, characteristic values are already presented):

$$
\begin{aligned}
f_{\mathrm{h}, \alpha, \mathrm{k}} & =\frac{f_{\mathrm{h}, 0, \mathrm{k}}}{k_{90} \sin ^{2} \alpha+\cos ^{2} \alpha}\left(\mathrm{N} / \mathrm{mm}^{2}\right), \text { where } \\
f_{\mathrm{h}, 0, \mathrm{k}} & =0.031 \cdot(1-0.015 d) \cdot \rho_{\mathrm{k}}^{1.16}\left(\mathrm{~N} / \mathrm{mm}^{2}\right),
\end{aligned}
$$

as the dowel's characteristic embedment strength when loaded parallel to the outer layer's grain direction, $d$ as the dowel diameter, $\rho_{\mathrm{k}}$ is the panel's characteristic density, $k_{90}=1.10$ is the ratio of the embedment strengths $f_{\mathrm{h}, \alpha=0^{\circ}, \mathrm{k}}$ and $f_{\mathrm{h}, \alpha=90^{\circ}, \mathrm{k}}$, and $\alpha$ is the angle between the load and the outer layer's grain direction. In ÖNORM B 1995-1-1, Annex K, the formulae given in Eqs 2 and 3 were adopted for determining the characteristic embedment strength of bolts and dowels, setting the characteristic density $\rho_{\mathrm{k}}$ to $400 \mathrm{~kg} / \mathrm{m}^{3}$ as a typical value for CLT made of Norway spruce and determined by Uibel and Blaß (2006):

$$
f_{\mathrm{h}, 0, \mathrm{k}}=32 \cdot(1-0.015 d)\left(\mathrm{N} / \mathrm{mm}^{2}\right) .
$$

For simplicity, this approach does not contain any information regarding the specific CLT layup. Thus, there are certain restrictions to be considered.
According to Uibel and Blaß (2006, 2013) (adopted in ÖNORM B 1995-1-1 as well), the maximum layer thickness $t_{1, \max }$ is set to $40 \mathrm{~mm}$, dowels or bolts have to be situated in at least $N=$ 3 layers and the ratio of layer thicknesses with different grain orientations has to fulfill the following condition:

$$
0.95<\frac{\sum t_{\mathrm{i}, x}}{\sum t_{\mathrm{i}, y}}<2.1,
$$

with $t_{\mathrm{i}, x}$ and $t_{\mathrm{i}, y}$ as single layer thicknesses parallel $(x)$ and perpendicular $(y)$ to the outer layer's grain direction. In case of dowels inserted in the edge of a CLT panel, Uibel and Blaß (2007) proposed the following equation to determine the characteristic embedment strength:

$$
f_{\mathrm{h}, \mathrm{k}}=0.0453(1-0.017 d) \rho_{\text {layer }, \mathrm{k}}^{0.91}\left(\mathrm{~N} / \mathrm{mm}^{2}\right),
$$

with $\rho_{\text {layer,k }}$ being the characteristic density of the layer where the fastener is located. By contrast to CLT face application, Eq 5 is missing in ÖNORM B 1995-1-1. The reason behind that is to avoid the application of bolts or dowels in CLT edges, which could result in excessive tensile stresses perpendicular to grain and consequently panel splitting.

With regard to the effective number of fasteners, the recommendations made by Uibel and Blaß (2013) that was to set $n_{\text {ef }}$ equal to $n$ (because the crosslamination structure of CLT serves as reinforcement against potential splitting in grain direction) has also been adopted in ÖNORM B 1995-1-1.

Nails and STS. For the design of laterally loaded (profiled) nails and STS located in the face or edge of CLT panels, Uibel and Blaß (2006, 2007) recommend determining the characteristic embedment strength as follows:

\section{CLT face application.}

$$
f_{\mathrm{h}, \mathrm{k}}=0.112 \cdot d^{-0.5} \cdot \rho_{\mathrm{k}}^{1.05}\left(\mathrm{~N} / \mathrm{mm}^{2}\right)
$$

\section{CLT edge application.}

$$
f_{\mathrm{h}, \mathrm{k}}=0.862 \cdot d^{-0.5} \cdot \rho_{\text {layer }, \mathrm{k}}^{0.56}\left(\mathrm{~N} / \mathrm{mm}^{2}\right)
$$


Here, $d$ is either the nominal nail diameter or the screw's outer thread diameter. It is worth mentioning that in case of CLT face application, Uibel and Blaß (2013) restrict Eq 7 to layups with $t_{1}$, $\mathrm{i} \leq 9 \mathrm{~mm}$. Consequently, the embedment strength of nails or screws located in the face of CLT panels with $t_{1, \mathrm{i}}$ exceeding this limit (which in fact is typical of most CLT layups, c.f. Brandner et al [2016]) shall be determined with approaches derived for solid timber, for instance, according to EN 1995-11, section 8. Identical to $f_{\mathrm{h}, \mathrm{k}}$ of dowels or bolts, in ÖNORM B 1995-1-1, Annex K, both Eqs 7 and 8 were adopted, with $\rho_{\mathrm{k}}=400 \mathrm{~kg} / \mathrm{m}^{3}$ and $\rho_{\text {layer, } \mathrm{k}}=$ $350 \mathrm{~kg} / \mathrm{m}^{3}$, the latter being the characteristic density of solid timber C24, c.f. EN 338 (CEN 2016):

\section{CLT face application.}

$$
f_{\mathrm{h}, \mathrm{k}}=60 \cdot d^{-0.5}\left(\mathrm{~N} / \mathrm{mm}^{2}\right)
$$

\section{CLT edge application (conservatively assuming fasteners driven in end grain).}

$$
f_{\mathrm{h}, \mathrm{k}}=20 \cdot d^{-0.5}\left(\mathrm{~N} / \mathrm{mm}^{2}\right)
$$

ÖNORM B 1995-1-1 limits the application of both formulae to panels with $t_{1, \mathrm{i}}>9 \mathrm{~mm}$, which is the exact opposite of the abovementioned requirement published by Uibel and Blaß (2013) and, thus, maybe a typo to be corrected in a next version. It is furthermore worth pointing out that Eqs 9 and 10 are only valid for nonpredrilled, profiled nails, whereas predrilled ones or smooth nails are not part of this NCI. This also applies to stapled CLT connections.

With regard to the effective number of fasteners, ÖNORM B 1995-1-1 does not provide any information for profiled nails, whereas in case of STS and in contrast to dowels or bolts, Eq 11 provided in EN 1995-1-1, section 8 was adopted:

$$
n_{\mathrm{ef}}=\min \left\{\begin{array}{c}
n \\
n^{0.9} \cdot \sqrt[4]{\frac{a_{1}}{13 \cdot d}},
\end{array}\right.
$$

where $n$ is the number of screws in a row and $a_{1}$ is the minimum spacing between two screws, both parallel to the outer layer's grain direction.

\section{Axial Resistance of Fasteners in CLT Connections}

With regard to the design of fasteners in CLT exposed to axial loading, related recommendations made by Uibel and Blaß $(2007,2013)$ are restricted to the application of STS and provide an empirical formula for determining the characteristic withdrawal capacity as follows:

$$
R_{\mathrm{ax}, \mathrm{s}, \mathrm{k}}=\frac{0.35 \cdot d^{0.8} \cdot l_{\mathrm{ef}}^{0.9} \cdot \rho_{\mathrm{k}}^{0.75}}{1.5 \cos ^{2} \varepsilon+\sin ^{2} \varepsilon} .(\mathrm{N})
$$

Here, $l_{\text {ef }}$ represents the inserted length of the threaded part of the screw, $\rho_{\mathrm{k}}$ the CLT panel's characteristic density and $\varepsilon$ the angle between screw axis and CLT face: (edge application: $\varepsilon=0^{\circ}$, face application: $\varepsilon=90^{\circ}$ ). The factor 1.5 in Eq 12 considers both, the difference of the characteristic densities, $\rho_{\mathrm{k}}$ and $\rho_{\text {layer, } \mathrm{k}}$, and the worst case scenario of inserting the screw parallel to the lamella's grain direction in case of CLT panel edge application. For screws arranged in the panel's edge, Eq 12 has been adopted in ÖNORM B 1995-1-1, again setting $\rho_{\mathrm{k}}$ to $400 \mathrm{~kg} / \mathrm{m}^{3}$ :

$$
F_{\mathrm{ax}, \mathrm{Rk}}=20 \cdot d^{0.8} \cdot l_{\mathrm{ef}}^{0.9}(\mathrm{~N})
$$

As reported in Pirnbacher and Schickhofer (2012), STS inserted parallel to the layer's grain direction show a poor performance with regard to longterm axial loading. If possible, this arrangement should be avoided. If not, ÖNORM B 1995-1-1 restricts the related application to partially threaded screws with a penetration depth in the panel's edge of at least $3 d+l_{\text {ef }}$. The reason behind this is that larger thread embedment was found to significantly increase the screw's long-term resistance, Pirnbacher and Schickhofer (2012) and Hübner (2013). In addition, ÖNORM B 1995-11 allows increasing $F_{\mathrm{ax}, \mathrm{Rk}}$ according to Eq 13 by a 1.25 factor if the angle between screw axis and grain direction is at least $45^{\circ}$.

By contrast to edge application, Eq 12 was not adopted for screws located in the face of CLT panels. In this case, ÖNORM B 1995-1-1 refers 




Figure 2. Definition of geometrical boundary conditions for the placement of fasteners in cross-laminated timber face and edges (from Ringhofer 2017).

to the common equation for determining the withdrawal capacity of STS in EN 1995-1-1, section 8 (originally derived by Blaß et al 2006):

$$
F_{\mathrm{ax}, \alpha, \mathrm{Rk}}=\frac{0.52 \cdot d^{0.5} \cdot l_{\mathrm{ef}}^{0.9} \cdot \rho_{\mathrm{k}}^{0.8}}{1.2 \cdot \sin ^{2} \alpha+\cos ^{2} \alpha}(\mathrm{N}),
$$

where $\alpha$ is the angle between screw axis and grain direction. In fact, there are two main reasons for this harmonization, which leads to slightly higher values for $F_{\mathrm{ax}, \alpha, \mathrm{Rk}}$ : first, experimental studies as reported in Ringhofer et al (2015) show that there is no significant difference in withdrawal capacity for screws in CLT or glulam if the CLT does not contain significant gaps. Second, the probability of placing a screw in a gap along its whole inserted thread length is much lower in case of face application than in case of edge application (Ringhofer 2017).

Because the commonly applied nail diameters are in a dimension similar to the gap widths occurring in CLT panels, ÖNORM B 1995-1-1 restricts their axial loading to CLT face application where a visible insertion is possible. The corresponding formula was adopted from Blaß and Uibel (2007), which provides background information for Uibel and Blaß (2006, 2007, 2013):

$$
F_{\mathrm{ax}, \mathrm{Rk}}=14 \cdot d^{0.6} \cdot l_{\mathrm{ef}}(\mathrm{N})
$$

$\mathrm{Eq} 14$ is of course only applicable for profiled nails with an appropriate resistance against axial

Table 1. Overview of minimum spacings and edge and end distances of dowel-type fasteners situated in cross-laminated timber.

\begin{tabular}{llllllll}
\hline Fastener type & Position & $a_{1}$ & $a_{2}$ & $a_{3, \mathrm{t}}$ & $a_{3, \mathrm{c}}$ & $a_{4, \mathrm{t}}$ & $a_{4, \mathrm{c}}$ \\
\hline Self-tapping & Face & $4 d$ & $2.5 d$ & $6 d$ & $6 d$ & $6 d$ & $2.5 d$ \\
screws & Edge & $10 d$ & $3 d$ & $12 d$ & $7 d$ & $5 d$ & $5 d$ \\
Nails (profiled) & Face & $(3+3 \cos \alpha) d$ & $3 d$ & $(7+3 \cos \alpha) d$ & $6 d$ & $(3+4 \sin \alpha)$ & $3 d$ \\
& Edge & $10 d$ & $3 d$ & $12 d$ & $7 d$ & - & $5 d$ \\
Bolts & Face & $\min [4 d,(3+2 \cos \alpha) d]$ & $4 d$ & $5 d$ & $4 d$ & $3 d$ \\
Dowels & Face & $(3+2 \cos \alpha) d$ & $3 d$ & $5 d$ & $\min [3 d, 4 d \sin \alpha]$ & $3 d$ & $3 d$ \\
\hline
\end{tabular}

Note: $\alpha$ represents the angle between the force and the outer layer's grain direction. 
Table 2. Additional geometrical requirements of nails and self-tapping screws (STS) situated in cross-laminated timber.

\begin{tabular}{|c|c|c|c|c|c|c|}
\hline Fastener type & $n_{\min }$ & Position & $t_{\min }$ & $t_{1, \text { min }}$ & $l_{\min }$ & $d_{\min }$ \\
\hline \multirow[t]{2}{*}{ STS } & $4^{\mathrm{a}}$ & Face & & & & $6 \mathrm{~mm}$ \\
\hline & & Edge & $10 d$ & $\begin{array}{l}d \leq 8 \mathrm{~mm}: 2 d \\
d \leq 8 \mathrm{~mm}: 3 d\end{array}$ & $10 d$ & $8 \mathrm{~mm}$ \\
\hline \multirow[t]{2}{*}{ Nails (profiled) } & 6 & Face & & & $8 d$ & $4 \mathrm{~mm}^{\mathrm{a}}$ \\
\hline & & Edge & $10 d$ & $\begin{array}{l}d \leq 8 \mathrm{~mm}: 2 d \\
d \leq 8 \mathrm{~mm}: 3 d\end{array}$ & $10 d$ & \\
\hline
\end{tabular}

${ }^{\mathrm{a}}$ To be only considered for axial loading.

loading. Furthermore, ÖNORM B 1995-1-1 limits both the nail diameter and the effective penetration depth to $d \geq 4 \mathrm{~mm}\left(F_{\mathrm{ax}, \mathrm{Rk}}\right.$ of nails with $d<6 \mathrm{~mm}$ has to be reduced by the factor 0.8 ) and $l_{\mathrm{ef}} \geq 8 \mathrm{~d}$.

The determination of the effective number of fasteners is similar to lateral loading conditions: Again, no rules are given for nails, whereas in the case of STS, the formula provided in EN 1995-1-1, section 8 was adopted:

$$
n_{\mathrm{ef}}=n^{0.9}
$$

Here, $n$ is the total number of screws in the connection.

\section{Placement of Fasteners in CLT}

In addition to the already discussed boundary conditions, which are directly linked to Eqs 2 to 16, ÖNORM B 1995-1-1 provides several geometrical requirements regarding the design of connections in CLT. They consist of minimum spacing $\left(a_{1}, a_{2}\right)$, edge $\left(a_{4(\mathrm{c}, \mathrm{t})}\right)$ and end $\left(a_{3(\mathrm{c}, \mathrm{t})}\right)$ distances, as well as minimum diameter $\left(d_{\min }\right)$, insertion length $\left(l_{\min }\right)$, and layer $\left(t_{1, \min }\right)$ and panel thicknesses $\left(t_{\min }\right)$. Based on the definitions illustrated in Fig 2 exemplarily for STS, Tables 1 and 2 summarize related characteristics depending on the fastener type and CLT face or edge application. The given values were again predominantly adopted from Blaß and Uibel (2007) where $a_{\mathrm{i}}$ was determined by means of screw (or nail) insertion tests verified by tensile-shear tests with laterally loaded fasteners.

In addition to these minimum conditions, ÖNORM B 1995-1-1 also contains maximum spacing $e_{\max }$, which ensures the compliance of geometrical boundary conditions by the building designers. In case of STS, they are as follows:

1. CLT-to-CLT connections: $e_{\max }=500 \mathrm{~mm}$,

2. CLT-to-GLT connections: $e_{\max }=500 \mathrm{~mm}$, and

3. CLT-to-steel member connections: $\mathrm{e}_{\max }=$ $750 \mathrm{~mm}$.

In case of profiled nails, $e_{\max }$ should not exceed $150 \mathrm{~mm}$ in general, whereas in case of dowels or bolts, no limitations are given.

\section{CLT CONNECTIONS IN THE CANADIAN TIMBER DESIGN STANDARD CSA O86}

\section{Background and Design Approach}

This section provides the background on the development of the design provisions for various types of connections in CLT in the Canadian timber design standard CSA O86 "Engineering Design in Wood" (CSA 2014). Although numerous studies of the performance of fastenings in CLT have been undertaken in Europe, Canada, Japan, and New Zealand, the primary reference for the derivation of design equations was the comprehensive work by German researchers Uibel and Blaß (2006, 2007). Test data obtained for Canadian-made CLT by Kennedy et al (2014) served for confirmation of the proposed design values.

Formulae proposed by Uibel and Blaß (2006, 2007 ) for the embedment and withdrawal strength of fasteners in CLT were compared with those given in CSA O86 for Canadian sawn timber and glulam. In the absence of more 
rigorous research results, the approach of the CSA O86 Technical Committee (TC) was to adopt equations providing more conservative strength values for bolts, dowels, lag screws, wood screws, and nails based on the comparisons. At first, the German equations were proposed for CLT in cases where they were more conservative than those in CSA O86 for sawn timber and glulam. However, discussions at the CSA O86 TC led to an agreement to avoid introducing new equations specific to CLT. Instead, for simplicity, it was decided to use the existing design embedment and withdrawal equations adjusted by a factor $\left(J_{\mathrm{X}}\right)$ for connections in CLT considering the differences in performance due to CLT-specific features such as edge joints and gaps between laminations, where appropriate. The values of $J_{\mathrm{X}}$ were calibrated to match the results obtained using the German equations as close as possible. The new design provisions for CLT and its connections have been implemented in the 2016 Supplement of CSA O86 (CSA 2014).

The following paragraphs provide results of the comparisons between the German equations for connections in CLT and the adjustments in the corresponding equations in CSA O86 for each type of fastener in the wood of three key Canadian species combinations used in the primary CLT layups as defined in CSA O86: Douglas Fir-Larch (DFL), SprucePine-Fir (SPF) and Northern Species (Northern). Comparisons of the proposed design values with the available test data are shown. Finally, the placement of fasteners in the panel face and edge of CLT accepted in CSA O86 is shown.

\section{Lateral Resistance}

Bolts, dowels and lag screws. To use Uibel and $\mathrm{Bla} ß$ proposed embedment equation in CSA O86, a factor of 0.8 is applied to adjust the characteristic values (10-min load duration) to standard-term load duration. Also, an adjustment factor of 0.765 is applied to convert the equations from the characteristic density at $12 \%$
MC to the mean oven-dry relative density $(G)$ used in CSA 086 as basis for calculation of resistance of connections at $15 \% \mathrm{MC}$. Therefore, Eqs 3 and 6 adjusted to the CSA O86 format and standard-term load duration would be expressed as follows:

\section{For panel face of CLT.}

$f_{\mathrm{P}}=55 G^{1.16}\left(1-0.015 d_{\mathrm{F}}\right)\left(\mathrm{N} / \mathrm{mm}^{2}\right)$,

for loading parallel to the grain of

the outer layers

$$
\begin{aligned}
f_{\mathrm{Q}}= & 50 G^{1.16}\left(1-0.015 d_{\mathrm{F}}\right)\left(\mathrm{N} / \mathrm{mm}^{2}\right), \text { for } \\
& \text { loading perpendicular to the grain } \\
& \text { of the outer layers }
\end{aligned}
$$

\section{For panel edge of CLT.}

$$
\begin{gathered}
f_{\|}=15\left(1-0.017 d_{\mathrm{F}}\right) G^{0.91}\left(\mathrm{~N} / \mathrm{mm}^{2}\right), \\
\text { for any loading angle to grain }
\end{gathered}
$$

The CSA O86 equations for the dowel embedment strength in the side grain of sawn timber and glulam are given as follows:

$$
\begin{aligned}
f_{\mathrm{P}}= & 50 G\left(1-0.01 d_{\mathrm{F}}\right)\left(\mathrm{N} / \mathrm{mm}^{2}\right), \\
& \text { for any loading parallel to the grain }(20) \\
f_{\mathrm{Q}}= & 22 G\left(1-0.01 d_{\mathrm{F}}\right)\left(\mathrm{N} / \mathrm{mm}^{2}\right), \\
& \text { for loading perpendicular to the grain }
\end{aligned}
$$

There are no provisions in CSA O86 for bolts and dowels installed in the end grain. For lag screws inserted parallel to the grain in the end grain of the main member, the lateral resistance shall be not greater than two-thirds $(0.67)$ or one-half $(0.5)$ of the lateral side grain resistance for perpendicularto-grain loading if wood side plates or steel side plates are used, respectively.

To keep the existing CSA O86 format, Eqs 20 and 21 were adjusted to allow calculations of the embedment strength for bolts and dowels in the panel face of CLT as follows: 


$$
f_{\mathrm{P}}=50 G\left(1-0.01 d_{\mathrm{F}}\right) J_{\mathrm{X}}
$$

for loading parallel to the grain

of the outer laminations

$$
f_{\mathrm{Q}}=22 G\left(1-0.01 d_{\mathrm{F}}\right) J_{\mathrm{X}}
$$

for loading perpendicular to the grain of the outer laminations

The values of $J_{\mathrm{X}}$ were calibrated to match the results obtained using the German equations as close as possible.

In case of the panel edge of CLT, fasteners are not necessarily inserted in the end grain of laminations and even when they are, there is a reinforcing effect from the adjacent cross laminations. Therefore, for bolts and dowels, which are subject to brittle failure modes check, an appropriate adjustment factor $J_{\mathrm{X}}$ for the embedment strength was chosen to match conservatively Eq 19. For lag screws, there is no explicit check for brittle failure modes in CSA O86; hence, it was decided to maintain the existing rules and end grain factors for conservatism.

Table 3 shows the comparisons between the embedment strength for bolts, dowels and lag screws installed perpendicular to the panel face of CLT and loaded parallel to the grain of outer laminations calculated with Eq 17 and with Eq 22 using the factor $J_{\mathrm{X}}=0.9$. An additional analysis of yielding equations showed that the greatest difference in the lateral resistance of fasteners would be in yielding modes $(b)$ and $(c)$ for bolts of 1-inch diameter where the embedment strength has the direct influence. In most other cases, yielding mode $(g)$ is dominating where the impact of the embedment strength is significantly less; hence, the deviation from the German equation was under $10 \%$. Considering that the axial tensioning component used in Eurocode 5 was ignored in these comparisons, it was decided that the adjustment factor is acceptable with sufficient conservatism.

Tables 4 and 5 show the comparisons between the embedment strength for bolts, dowels, and lag screws installed perpendicular to the panel face of CLT and loaded perpendicular to the grain of outer laminations calculated with $\mathrm{Eq} 18$ and with Eq 23 using the factors $J_{\mathrm{X}}=1.8$ and $J_{\mathrm{X}}=1.0$, respectively. It is evident from Table 4 that $J_{\mathrm{X}}=$ 1.8 would have similar impact on the lateral resistance perpendicular to grain as $J_{\mathrm{X}}=0.9$ on the resistance parallel to grain. However, it was decided to use $J_{\mathrm{X}}=1.0$ for conservatism. An additional analysis of yielding equations showed that the lateral resistance is underestimated by 25 $40 \%$ relative to the German equations without accounting for the axial tensioning effect.

Table 6 shows the comparisons between the embedment strength for bolts, dowels, and lag screws installed in the panel edge of the CLT with the fastener axis parallel to the panel face calculated with the Uibel and Blaß (2007) and the adjusted CSA O86 equations with the factor $J_{\mathrm{X}}=$ 0.6 . In this case, the equations are applicable to any load direction with respect to the grain. An additional analysis of yielding equations showed that the equation yields slightly conservative values of lateral resistance with the difference from the German equations less than $10 \%$ not accounting for the axial tensioning effect.

Table 3. Embedment strength, $f_{\mathrm{iP}}$, for fastener bearing parallel to the grain of laminations in panel face of cross-laminated

\begin{tabular}{|c|c|c|c|c|c|c|c|c|c|c|}
\hline \multirow{2}{*}{\multicolumn{2}{|c|}{$\begin{array}{l}\text { Diameter (bolt, dowel, } \\
\text { and lag screw) }\end{array}$}} & \multicolumn{3}{|c|}{ CSA O86 (MPa) } & \multicolumn{3}{|c|}{ Uibel and Blaß (MPa) } & \multicolumn{3}{|c|}{ CSA O86/Uibel and Blaß } \\
\hline & & \multirow{2}{*}{$\begin{array}{l}\text { DFL } \\
0.49\end{array}$} & \multirow{2}{*}{$\begin{array}{l}\text { SPF } \\
0.42\end{array}$} & \multirow{2}{*}{$\begin{array}{r}\text { North } \\
0.35\end{array}$} & \multirow{2}{*}{$\begin{array}{l}\text { DFL } \\
0.49\end{array}$} & \multirow{2}{*}{$\begin{array}{l}\text { SPF } \\
0.42\end{array}$} & \multirow{2}{*}{$\begin{array}{c}\text { North } \\
0.35\end{array}$} & \multirow{2}{*}{$\begin{array}{c}\text { DFL } \\
0.49\end{array}$} & \multirow{2}{*}{$\begin{array}{c}\text { SPF } \\
0.42\end{array}$} & \multirow{2}{*}{$\begin{array}{l}\text { North } \\
0.35\end{array}$} \\
\hline inch & $\mathrm{mm}$ & & & & & & & & & \\
\hline 0.25 & 6.35 & 20.65 & 17.70 & 14.75 & 21.8 & 18.2 & 14.7 & 0.95 & 0.97 & 1.00 \\
\hline 0.38 & 9.53 & 19.95 & 17.10 & 14.25 & 20.6 & 17.2 & 13.9 & 0.97 & 0.99 & 1.02 \\
\hline 0.50 & 12.70 & 19.25 & 16.50 & 13.75 & 19.5 & 16.3 & 13.2 & 0.99 & 1.01 & 1.04 \\
\hline 0.63 & 15.88 & 18.55 & 15.90 & 13.25 & 18.3 & 15.3 & 12.4 & 1.01 & 1.04 & 1.07 \\
\hline 0.75 & 19.05 & 17.85 & 15.30 & 12.75 & 17.2 & 14.4 & 11.6 & 1.04 & 1.07 & 1.10 \\
\hline 1 & 25.40 & 16.45 & 14.10 & 11.75 & 14.9 & 12.4 & 10.1 & 1.11 & 1.13 & 1.17 \\
\hline
\end{tabular}
timber (Eq 22 vs Eq 17), $J_{\mathrm{X}}=0.9$.

DFL, Douglas Fir-Larch; SPF, Spruce-Pine-Fir; North, Northern Species. 
Table 4. Embedment strength, $f_{\mathrm{iQ}}$, for fastener bearing perpendicular to the grain of laminations in panel face of crosslaminated timber (Eq 23 vs Eq 18) $J_{\mathrm{X}}=1.8$.

\begin{tabular}{|c|c|c|c|c|c|c|c|c|c|c|}
\hline \multirow{2}{*}{\multicolumn{2}{|c|}{$\begin{array}{c}\text { Diameter (bolt, } \\
\text { dowel, and lag screw) }\end{array}$}} & \multicolumn{3}{|c|}{ CSA O86 (MPa) } & \multicolumn{3}{|c|}{ Uibel and Blaß (MPa) } & \multicolumn{3}{|c|}{ CSA O86/Uibel and Blaß } \\
\hline & & \multirow{2}{*}{$\begin{array}{l}\text { DFL } \\
0.49\end{array}$} & \multirow{2}{*}{$\begin{array}{l}\text { SPF } \\
0.42\end{array}$} & \multirow{2}{*}{$\begin{array}{c}\text { North } \\
0.35\end{array}$} & \multirow{2}{*}{$\begin{array}{l}\text { DFL } \\
0.49\end{array}$} & \multirow{2}{*}{$\begin{array}{l}\text { SPF } \\
0.42\end{array}$} & \multirow{2}{*}{$\begin{array}{c}\text { North } \\
0.35\end{array}$} & \multirow{2}{*}{$\begin{array}{l}\text { DFL } \\
0.49\end{array}$} & \multirow{2}{*}{$\frac{\text { SPF }}{0.42}$} & \multirow{2}{*}{$\frac{\text { North }}{0.35}$} \\
\hline inch & $\mathrm{mm}$ & & & & & & & & & \\
\hline 0.25 & 6.35 & 18.17 & 15.58 & 12.98 & 19.8 & 16.5 & 13.4 & 0.92 & 0.94 & 0.97 \\
\hline 0.38 & 9.53 & 17.56 & 15.05 & 12.54 & 18.7 & 15.7 & 12.7 & 0.94 & 0.96 & 0.99 \\
\hline 0.50 & 12.70 & 16.94 & 14.52 & 12.10 & 17.7 & 14.8 & 12.0 & 0.96 & 0.98 & 1.01 \\
\hline 0.63 & 15.88 & 16.32 & 13.99 & 11.66 & 16.7 & 13.9 & 11.3 & 0.98 & 1.00 & 1.03 \\
\hline 0.75 & 19.05 & 15.71 & 13.46 & 11.22 & 15.6 & 13.1 & 10.6 & 1.01 & 1.03 & 1.06 \\
\hline 1 & 25.40 & 14.48 & 12.41 & 10.34 & 13.5 & 11.3 & 9.2 & 1.07 & 1.10 & 1.13 \\
\hline
\end{tabular}

DFL, Douglas Fir-Larch; SPF, Spruce-Pine-Fir; North, Northern Species.

Additional analysis has shown that applying the current CSA O86 provisions for lag screws in the end grain to those inserted in the panel edge of CLT yields largely conservative results in comparison with Uibel and Blaß (2007). For CLTto-CLT edge-to-face connections with lag screws, the lateral resistance with the embedment strength of both members taken from $\mathrm{Eq} 23$ with $J_{\mathrm{X}}=1.0$, is $36-50 \%$ less than that predicted by the German equations. For CLT connections with lag screws and steel side plates, the lateral resistance is under predicted between $20 \%$ and $40 \%$. In these comparisons, the axial tensioning effect was ignored, which would allow significant increase of the lateral resistance of threaded fasteners according to Eurocode 5. If it were included in the European equations, the discrepancy in the predictions would be even greater.

Nails, spikes, and wood screws. The proposed Eqs 7 and 8 by Uibel and Blaß apply to any loading angle to the grain. Using the format conversion shown in the previous section, Eqs 7 and 8 adjusted to the CSA O86 standard-term load duration would be expressed as follows:

$$
\begin{aligned}
f_{\perp}= & 96 d_{\mathrm{F}}^{-0.5} G^{1.05}\left(\mathrm{~N} / \mathrm{mm}^{2}\right), \\
& \text { for panel face of CLT } \\
f_{\|}= & 28 d_{\mathrm{F}}^{-0.5} G^{0.56}\left(\mathrm{~N} / \mathrm{mm}^{2}\right), \\
& \text { for panel edge of CLT }
\end{aligned}
$$

The CSA O86 equations for the embedment strength equations for nails, spikes, and wood screws inserted in the side grain of sawn timber and glulam are given as follows:

$$
\begin{aligned}
f_{1,2}= & 50 G\left(1-0.01 d_{\mathrm{F}}\right)\left(\mathrm{N} / \mathrm{mm}^{2}\right), \\
& \text { for side and main members } \\
& \text { made of lumber }
\end{aligned}
$$

$$
f_{3}=110 G^{1.8}\left(1-0.01 d_{\mathrm{F}}\right)\left(\mathrm{N} / \mathrm{mm}^{2}\right),
$$

for main member where failure

\begin{tabular}{|c|c|c|c|c|c|c|c|c|c|c|}
\hline \multirow{2}{*}{\multicolumn{2}{|c|}{$\begin{array}{l}\text { Diameter (bolt, dowel, } \\
\text { and lag screw) }\end{array}$}} & \multicolumn{3}{|c|}{ CSA O86 (MPa) } & \multicolumn{3}{|c|}{ Uibel and Blaß (MPa) } & \multicolumn{3}{|c|}{ CSA O86/Uibel and Blaß } \\
\hline & & \multirow{2}{*}{$\begin{array}{l}\text { DFL } \\
0.49\end{array}$} & \multirow{2}{*}{$\begin{array}{c}\text { SPF } \\
0.42\end{array}$} & \multirow{2}{*}{$\begin{array}{c}\text { North } \\
0.35\end{array}$} & \multirow{2}{*}{$\begin{array}{l}\text { DFL } \\
0.49\end{array}$} & \multirow{2}{*}{$\begin{array}{l}\text { SPF } \\
0.42\end{array}$} & \multirow{2}{*}{$\begin{array}{c}\text { North } \\
0.35\end{array}$} & \multirow{2}{*}{$\begin{array}{c}\text { DFL } \\
0.49\end{array}$} & \multirow{2}{*}{$\begin{array}{c}\text { SPF } \\
0.42\end{array}$} & \multirow{2}{*}{$\begin{array}{l}\text { North } \\
0.35\end{array}$} \\
\hline inch & $\mathrm{mm}$ & & & & & & & & & \\
\hline 0.25 & 6.35 & 10.10 & 8.65 & 7.21 & 19.8 & 16.5 & 13.4 & 0.51 & 0.52 & 0.54 \\
\hline 0.38 & 9.53 & 9.75 & 8.36 & 6.97 & 18.7 & 15.7 & 12.7 & 0.52 & 0.53 & 0.55 \\
\hline 0.50 & 12.70 & 9.41 & 8.07 & 6.72 & 17.7 & 14.8 & 12.0 & 0.53 & 0.55 & 0.56 \\
\hline 0.63 & 15.88 & 9.07 & 7.77 & 6.48 & 16.7 & 13.9 & 11.3 & 0.54 & 0.56 & 0.57 \\
\hline 0.75 & 19.05 & 8.73 & 7.48 & 6.23 & 15.6 & 13.1 & 10.6 & 0.56 & 0.57 & 0.59 \\
\hline 1 & 25.40 & 8.04 & 6.89 & 5.74 & 13.5 & 11.3 & 9.2 & 0.59 & 0.61 & 0.63 \\
\hline
\end{tabular}

$$
\text { is fastener yielding }
$$

Like in the case of bolts and dowels, Eqs 26 and 27 were adjusted for the fasteners inserted in the panel face of CLT as follows:

Table 5. Embedment strength, $f_{\mathrm{iQ}}$, for fastener bearing perpendicular to the grain of laminations in panel face of crosslaminated timber (Eq $23 \mathrm{vs} \mathrm{Eq} \mathrm{18),} J_{\mathrm{X}}=1.0$.

DFL, Douglas Fir-Larch; SPF, Spruce-Pine-Fir; North, Northern Species. 
Table 6. Embedment strength, $f_{\mathrm{i} \theta}$, for fastener bearing at any angle to the grain of laminations in panel edge of crosslaminated timber (Eq 23 vs Eq 19), $J_{\mathrm{X}}=0.6$.

\begin{tabular}{|c|c|c|c|c|c|c|c|c|c|c|}
\hline \multirow{2}{*}{\multicolumn{2}{|c|}{$\begin{array}{c}\text { Diameter (bolt and } \\
\text { dowel) }\end{array}$}} & \multicolumn{3}{|c|}{ CSA O86 (MPa) } & \multicolumn{3}{|c|}{ Uibel and Blaß (MPa) } & \multicolumn{3}{|c|}{ CSA O86/Uibel and Blaß } \\
\hline & & \multirow{2}{*}{$\begin{array}{l}\text { DFL } \\
0.49\end{array}$} & \multirow{2}{*}{$\begin{array}{c}\text { SPF } \\
0.42\end{array}$} & \multirow{2}{*}{$\begin{array}{l}\text { North } \\
0.35\end{array}$} & \multirow{2}{*}{$\begin{array}{l}\mathrm{DFL} \\
0.49\end{array}$} & \multirow{2}{*}{$\begin{array}{c}\text { SPF } \\
0.42\end{array}$} & \multirow{2}{*}{$\begin{array}{l}\text { North } \\
0.35\end{array}$} & \multirow{2}{*}{$\begin{array}{c}\text { DFL } \\
0.49\end{array}$} & \multirow{2}{*}{$\begin{array}{c}\text { SPF } \\
0.42\end{array}$} & \multirow{2}{*}{$\begin{array}{l}\text { North } \\
0.35\end{array}$} \\
\hline inch & $\mathrm{mm}$ & & & & & & & & & \\
\hline 0.25 & 6.35 & 6.1 & 5.2 & 4.3 & 7.0 & 6.1 & 5.1 & 0.87 & 0.86 & 0.84 \\
\hline 0.38 & 9.53 & 5.9 & 5.0 & 4.2 & 6.6 & 5.7 & 4.8 & 0.90 & 0.88 & 0.87 \\
\hline 0.50 & 12.70 & 5.7 & 4.9 & 4.1 & 6.1 & 5.3 & 4.5 & 0.92 & 0.91 & 0.90 \\
\hline 0.63 & 15.88 & 5.5 & 4.7 & 3.9 & 5.7 & 5.0 & 4.2 & 0.96 & 0.94 & 0.93 \\
\hline 0.75 & 19.05 & 5.3 & 4.5 & 3.8 & 5.3 & 4.6 & 3.9 & 0.99 & 0.98 & 0.96 \\
\hline 1 & 25.40 & 4.8 & 4.2 & 3.5 & 4.5 & 3.9 & 3.3 & 1.09 & 1.07 & 1.06 \\
\hline
\end{tabular}

DFL, Douglas Fir-Larch; SPF, Spruce-Pine-Fir; North, Northern Species.

$$
\begin{gathered}
f_{1,2}=50 G\left(1-0.01 d_{\mathrm{F}}\right) J_{\mathrm{X}}\left(\mathrm{N} / \mathrm{mm}^{2}\right) \\
f_{3}=110 G^{1.8}\left(1-0.01 d_{\mathrm{F}}\right) J_{\mathrm{X}}\left(\mathrm{N} / \mathrm{mm}^{2}\right)
\end{gathered}
$$

Tables 5 and 6 show the comparisons between the embedment strength for nails, spikes, and wood screws inserted perpendicular to the panel face of CLT calculated with Eq 24 and with the adjusted CSA 086 equations for $f_{1,2}$ (Eq 28) and $f_{3}(\mathrm{Eq} 29)$ using $J_{\mathbf{X}}=0.9$ and $J_{\mathbf{X}}=$ 0.8 , respectively. An additional analysis of yielding equations for connections with nails and spikes with light gauge and mild steel side plates showed the ratio of $0.98 \pm 0.13$ (CSA O86/German equations). For wood screws, the ratio was $0.98 \pm 0.11$. The axial tensioning component used in Eurocode 5 was ignored in these comparisons, although it can be shown that it would increase the lateral resistance of the studied connections with wood screws by an additional $13 \%$, on the average. Therefore, it was decided that the adjustment factors are acceptable with sufficient conservatism.

In CSA O86, the lateral resistance of connections with nails, spikes, and wood screws inserted in the end grain of sawn timber and glulam members is adjusted using the end grain factor $J_{\mathrm{E}}=0.67$. Except for some fasteners in DFL, this reduction is acceptable for the most practical connection configurations with CLT. Furthermore, it appears that no further reduction of the embedment strength of CLT is needed for wood screws, especially if the axial tensioning effect were included in the European equations for the comparison, which would add more than $20 \%$, on the average, to the lateral resistance. However, for conservatism and considering that the withdrawal of nails is not considered in CSA O86 except for the shortterm loads, it was decided to apply the same adjustment factors $J_{\mathrm{X}}=0.9$ for $f_{1}$ and $f_{2}$ and $J_{\mathrm{X}}=0.8$ for $f_{3}$ for the embedment strength in the panel edge as it was carried out for the panel face of CLT (Tables 7 and 8).

\section{Withdrawal Resistance}

Same conversion as described previously was applied to derive the withdrawal resistance in CSA O86 format. In addition, to preserve the use of the penetration length without an exponent, an additional adjustment factor of 0.61 was applied as the regression coefficient between $l_{\mathrm{ef}}^{0.9}$ and $l_{\mathrm{ef}}$ in the range between $25 \mathrm{~mm}$ and $200 \mathrm{~mm}$. After that, Eq 12 can be used to calculate the basic withdrawal resistance of screws in the CSA O86 format as follows:

$$
y_{\mathrm{w}}=25 d_{\mathrm{F}}{ }^{0.8} G^{0.75}(\mathrm{~N} / \mathrm{mm})
$$

In CSA O86, the basic withdrawal resistance of lag screws and wood screws from the side grain of sawn timber and glulam is calculated as follows:

$$
y_{\mathrm{w}}=59 d_{\mathrm{F}}^{0.82} G^{1.77}(\mathrm{~N} / \mathrm{mm})
$$

Applying the adjustment factor $J_{\mathrm{X}}$ for fasteners inserted into the panel face of CLT, the equation transforms into: 
Table 7. Embedment strength, $f_{1}$ and $f_{2}$, for fastener bearing at any angle to the grain of laminations in panel face of crosslaminated timber (Eq 28 vs Eq 24), $J_{\mathrm{X}}=0.9$.

\begin{tabular}{|c|c|c|c|c|c|c|c|c|c|c|}
\hline \multirow{2}{*}{\multicolumn{2}{|c|}{ Fastener/diameter }} & \multicolumn{3}{|c|}{ CSA O86 (MPa) } & \multicolumn{3}{|c|}{ Uibel and Blaß (MPa) } & \multicolumn{3}{|c|}{ CSA O86/Uibel and Blaß } \\
\hline & & DFL & SPF & North & DFL & SPF & North & DFL & SPF & North \\
\hline \multirow{5}{*}{ Nails and spikes } & $d_{\mathrm{F}}(\mathrm{mm})$ & 0.49 & 0.42 & 0.35 & 0.49 & 0.42 & 0.35 & 0.49 & 0.42 & 0.35 \\
\hline & 2.84 & 21.4 & 18.4 & 15.3 & 24.2 & 20.6 & 17.0 & 0.88 & 0.89 & 0.90 \\
\hline & 3.25 & 21.3 & 18.3 & 15.2 & 22.7 & 19.3 & 15.9 & 0.94 & 0.95 & 0.96 \\
\hline & 3.66 & 21.2 & 18.2 & 15.2 & 21.4 & 18.2 & 15.0 & 0.99 & 1.00 & 1.01 \\
\hline & 4.06 & 21.2 & 18.1 & 15.1 & 20.3 & 17.2 & 14.2 & 1.04 & 1.05 & 1.06 \\
\hline \multirow{7}{*}{ Wood screws } & 4.88 & 21.0 & 18.0 & 15.0 & 18.5 & 15.7 & 13.0 & 1.13 & 1.14 & 1.15 \\
\hline & 5.89 & 20.8 & 17.8 & 14.8 & 16.8 & 14.3 & 11.8 & 1.23 & 1.24 & 1.25 \\
\hline & 7.01 & 20.5 & 17.6 & 14.6 & 15.4 & 13.1 & 10.8 & 1.33 & 1.34 & 1.35 \\
\hline & 3.5 & 21.3 & 18.2 & 15.2 & 24.3 & 20.6 & 17.0 & 0.88 & 0.88 & 0.89 \\
\hline & 4.16 & 21.1 & 18.1 & 15.1 & 22.3 & 18.9 & 15.6 & 0.95 & 0.96 & 0.97 \\
\hline & 4.82 & 21.0 & 18.0 & 15.0 & 20.7 & 17.6 & 14.5 & 1.02 & 1.02 & 1.03 \\
\hline & 5.48 & 20.8 & 17.9 & 14.9 & 19.4 & 16.5 & 13.6 & 1.07 & 1.08 & 1.09 \\
\hline
\end{tabular}

DFL, Douglas Fir-Larch; SPF, Spruce-Pine-Fir; North, Northern Species.

$$
y_{\mathrm{w}}=59 d_{\mathrm{F}}^{0.82} G^{1.77} J_{\mathrm{X}}(\mathrm{N} / \mathrm{mm})
$$

Table 9 shows the comparisons of results between Eqs 30 and 32 for wood screws and lag screws in withdrawal from panel face of CLT taking $J_{\mathrm{X}}=$ 0.9 . With this factor, the withdrawal resistance of denser species (DFL) is slightly overpredicted (9\% or less), whereas the predictions for wood of lower density (SPF and Northern) are underpredicted relative to the German model. It was decided to use this factor until more research information on Canadian CLT is available.

In CSA O86, the basic withdrawal resistance of nails and spikes from the side grain of sawn timber and glulam is calculated as follows:

$$
y_{\mathrm{w}}=16.4 d_{F}^{0.82} G^{2.2}(\mathrm{~N} / \mathrm{mm})
$$

Eq 33 is valid for short-term load duration only and it is applicable to smooth shank fasteners. Although there is no reference for calibration of the withdrawal resistance of nails and spikes from CLT, it was decided to apply the same adjustment factor $J_{X}=0.9$ in Eq 33 as for threaded fasteners until further information becomes available.

From Eq 12, it follows that the withdrawal resistance of STS driven into the panel edge of CLT is two-thirds of those driven into the panel face. In CSA O86, the withdrawal resistance of lag screws inserted into the end grain of wood is reduced by the end grain factor $J_{\mathrm{E}}=0.75$. Given

Table 8. Embedment strength, $f_{3}$, for fastener bearing at any angle to grain of laminations in panel face of cross-laminated

\begin{tabular}{|c|c|c|c|c|c|c|c|c|c|c|}
\hline \multirow{2}{*}{\multicolumn{2}{|c|}{ Fastener/diameter }} & \multicolumn{3}{|c|}{ CSA O86 (MPa) } & \multicolumn{3}{|c|}{ Uibel and Blaß (MPa) } & \multicolumn{3}{|c|}{ CSA O86/Uibel and Blaß } \\
\hline & & DFL & SPF & North & DFL & SPF & North & DFL & SPF & North \\
\hline \multirow{5}{*}{ Nails and spikes } & $d_{\mathrm{F}}(\mathrm{mm})$ & 0.49 & 0.42 & 0.35 & 0.49 & 0.42 & 0.35 & 0.49 & 0.42 & 0.35 \\
\hline & 2.84 & 23.7 & 17.9 & 12.9 & 26.9 & 22.9 & 18.9 & 0.88 & 0.78 & 0.68 \\
\hline & 3.25 & 23.6 & 17.9 & 12.9 & 25.2 & 21.4 & 17.7 & 0.94 & 0.83 & 0.73 \\
\hline & 3.66 & 23.5 & 17.8 & 12.8 & 23.7 & 20.2 & 16.7 & 0.99 & 0.88 & 0.77 \\
\hline & 4.06 & 23.4 & 17.7 & 12.8 & 22.5 & 19.2 & 15.8 & 1.04 & 0.92 & 0.81 \\
\hline \multirow{7}{*}{ Wood screws } & 4.88 & 23.2 & 17.6 & 12.6 & 20.5 & 17.5 & 14.4 & 1.13 & 1.00 & 0.88 \\
\hline & 5.89 & 22.9 & 17.4 & 12.5 & 18.7 & 15.9 & 13.1 & 1.23 & 1.09 & 0.95 \\
\hline & 7.01 & 22.7 & 17.2 & 12.4 & 17.1 & 14.6 & 12.0 & 1.32 & 1.18 & 1.03 \\
\hline & 3.5 & 23.5 & 17.8 & 12.8 & 24.3 & 20.6 & 17.0 & 0.97 & 0.86 & 0.75 \\
\hline & 4.16 & 23.4 & 17.7 & 12.7 & 22.3 & 18.9 & 15.6 & 1.05 & 0.93 & 0.82 \\
\hline & 4.82 & 23.2 & 17.6 & 12.7 & 20.7 & 17.6 & 14.5 & 1.12 & 1.00 & 0.87 \\
\hline & 5.48 & 23.0 & 17.5 & 12.6 & 19.4 & 16.5 & 13.6 & 1.19 & 1.06 & 0.92 \\
\hline
\end{tabular}
timber (Eq 29 vs Eq 24), $J_{\mathrm{X}}=0.8$.

DFL, Douglas Fir-Larch; SPF, Spruce-Pine-Fir; North, Northern Species. 
Table 9. Basic withdrawal resistance, $y_{\mathrm{w}}$, of fasteners from panel face of cross-laminated timber $(\mathrm{Eq} 31 \mathrm{vs}$ Eq 30$), J_{\mathrm{X}}=0.9$.

\begin{tabular}{|c|c|c|c|c|c|c|c|c|c|c|}
\hline \multirow{2}{*}{\multicolumn{2}{|c|}{ Fastener/diameter }} & \multicolumn{3}{|c|}{ CSA O86 (N/mm) } & \multicolumn{3}{|c|}{ Uibel and $\mathrm{Blaß}(\mathrm{N} / \mathrm{mm})$} & \multicolumn{3}{|c|}{ CSA O86/Uibel and Blaß } \\
\hline & & DFL & SPF & North & DFL & SPF & North & DFL & SPF & North \\
\hline & $d_{\mathrm{F}}(\mathrm{mm})$ & 0.49 & 0.42 & 0.35 & 0.49 & 0.42 & 0.35 & 0.49 & 0.42 & 0.35 \\
\hline \multirow[t]{4}{*}{ Wood screws } & 3.5 & 42.0 & 31.9 & 23.1 & 39.9 & 35.5 & 31.0 & 1.05 & 0.90 & 0.75 \\
\hline & 4.16 & 48.4 & 36.8 & 26.7 & 45.8 & 40.8 & 35.6 & 1.06 & 0.90 & 0.75 \\
\hline & 4.82 & 54.6 & 41.5 & 30.1 & 51.5 & 45.9 & 40.0 & 1.06 & 0.90 & 0.75 \\
\hline & 5.48 & 60.6 & 46.1 & 33.4 & 57.1 & 50.9 & 44.4 & 1.06 & 0.91 & 0.75 \\
\hline \multirow[t]{6}{*}{ Lag screws } & 6.35 & 68.4 & 52.1 & 37.7 & 64 & 57 & 50 & 1.06 & 0.91 & 0.76 \\
\hline & 9.53 & 95.4 & 72.6 & 52.6 & 89 & 79 & 69 & 1.07 & 0.92 & 0.76 \\
\hline & 12.70 & 120.7 & 91.9 & 66.6 & 112 & 100 & 87 & 1.08 & 0.92 & 0.77 \\
\hline & 15.88 & 145.0 & 110.4 & 79.9 & 134 & 119 & 104 & 1.08 & 0.93 & 0.77 \\
\hline & 19.05 & 168.4 & 128.2 & 92.8 & 155 & 138 & 120 & 1.09 & 0.93 & 0.77 \\
\hline & 25.40 & 213.2 & 162.3 & 117.5 & 195 & 173 & 151 & 1.09 & 0.94 & 0.78 \\
\hline
\end{tabular}

DFL, Douglas Fir-Larch; SPF, Spruce-Pine-Fir; North, Northern Species.

that the German equation provides more conservative results, it was decided to use $J_{\mathrm{E}}=0.67$ for lag screws in the panel edge of CLT. According to CSA O86, nails and wood screws driven through the end grain shall not be considered to carry load in withdrawal. Where designs rely on withdrawal resistance of fasteners in the panel edge of CLTs, precaution shall be taken to ensure that side grain penetration occurs.

\section{Comparison with Test Results in Canada}

Kennedy et al (2014a,b,c) conducted a large experimental campaign at Université Laval and FPInnovations under the NEWBuildS network focusing on the withdrawal resistance and the embedment strength of dowel-type fasteners in Canadian sawn timber, glulam, and CLT. Among others, the experimental program included 360 tests with lag screws and 120 tests with STS with diameters ranging from $6.0 \mathrm{~mm}$ to $19.1 \mathrm{~mm}$ loaded in withdrawal from the panel face of CLT from two Canadian producers. A comparison of the factored withdrawal resistance of lag screws using Eqs 30 and 31 vs test results showed that both produce similar predictions and tend to slightly underestimate the withdrawal resistance of lag screws driven perpendicular to the panel face of CLTs, especially for larger fasteners and longer penetration depths (Fig 3).

Based on the comparisons, it was recommended using the equations that provide more conservative withdrawal strength values for lag screws, wood screws, and nails. As discussed earlier, in cases where the CSA O86 approach was more conservative, current withdrawal equations for sawn timber and glulam were adopted. In other cases, where the German equations resulted in lower withdrawal resistances, an adjustment factor $\left(J_{\mathrm{X}}\right)$ corresponding to the ratio of the German and the CSA O86 design approach was applied to the CSA O86 withdrawal equations. Recent studies by Abukari et al (2012) and Kennedy et al (2014) have shown that Eq 31 is also applicable to STS, which are beyond the scope of the current edition of CSA O86.

\section{Placement of Fasteners in CLT}

The minimum spacing requirements for the fasteners installed in panel face of CLT are the same as those given in CSA O86 for other wood products. However, a new clause has been introduced to provide requirements on the placement of bolts and dowels installed in the panel edge of CLTs (Fig 4). The same requirements are given for lag screws as they are also installed with predrilling. Spacing requirements for nails, spikes, and wood screws in the panel edge of CLTs are also provided. These requirements are intended to limit splitting of wood and are based on the recommendations of Uibel and Blaß (2007) for dowel-type fasteners and European technical approvals (eg ETA-11/0030). 

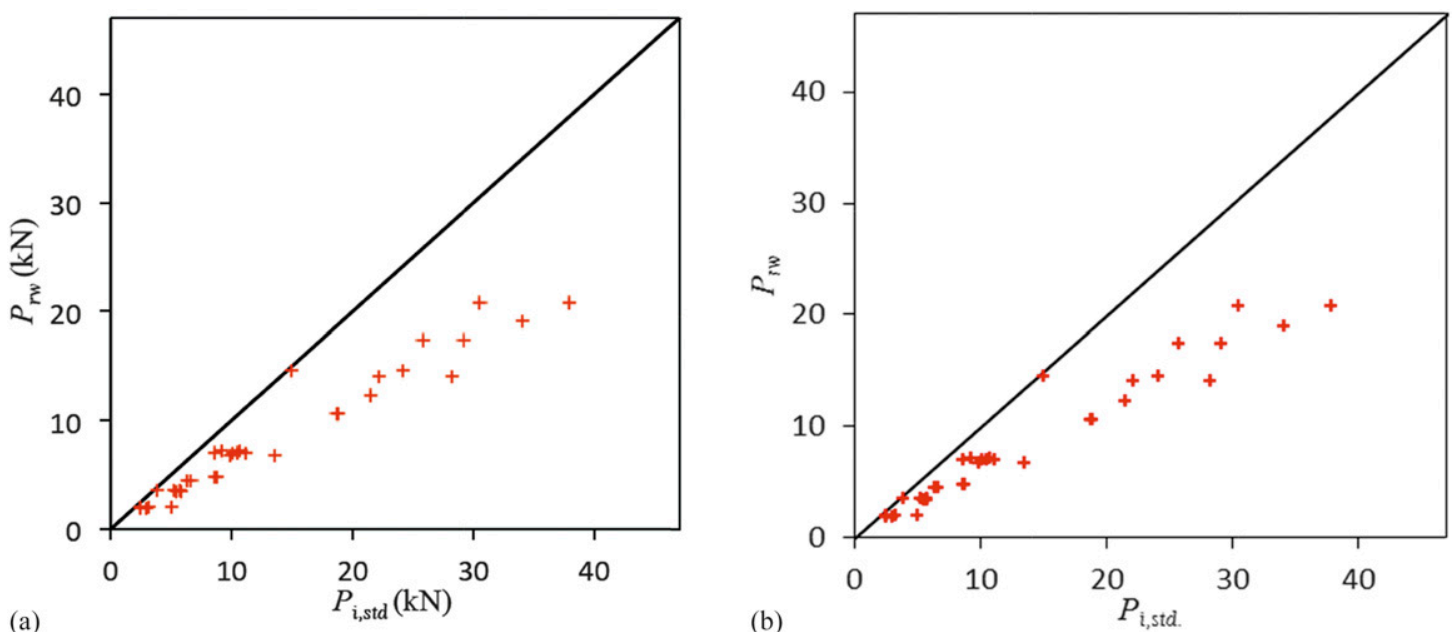

Figure 3. Comparison of factored withdrawal resistance using (a) Eq 31 and (b) Eq 30 vs test results (from Kennedy et al 2014).

\section{CLT CONNECTION IN THE UNITED STATES TIMBER DESIGN STANDARD (NDS)}

This section provides background on the design provisions for dowel-type fastener connections in CLT panels in the 2015 Edition of the National Design Specification ${ }^{\circledR}\left(N D S^{\circledR}\right)$ for Wood Construction (AWC 2015). The design of dowel-type fastener connections in CLT panels, in accordance with the NDS, follows basic design requirements applicable to connection design using solid sawn lumber with additional provisions to account for the effect of crossing layers in the panel make-up. Connection design values are obtained using the existing design formula and adjustment factors in the NDS. Unique aspects of CLT panels from a connection design perspective are the presence of alternating direction of wood grain through the panel
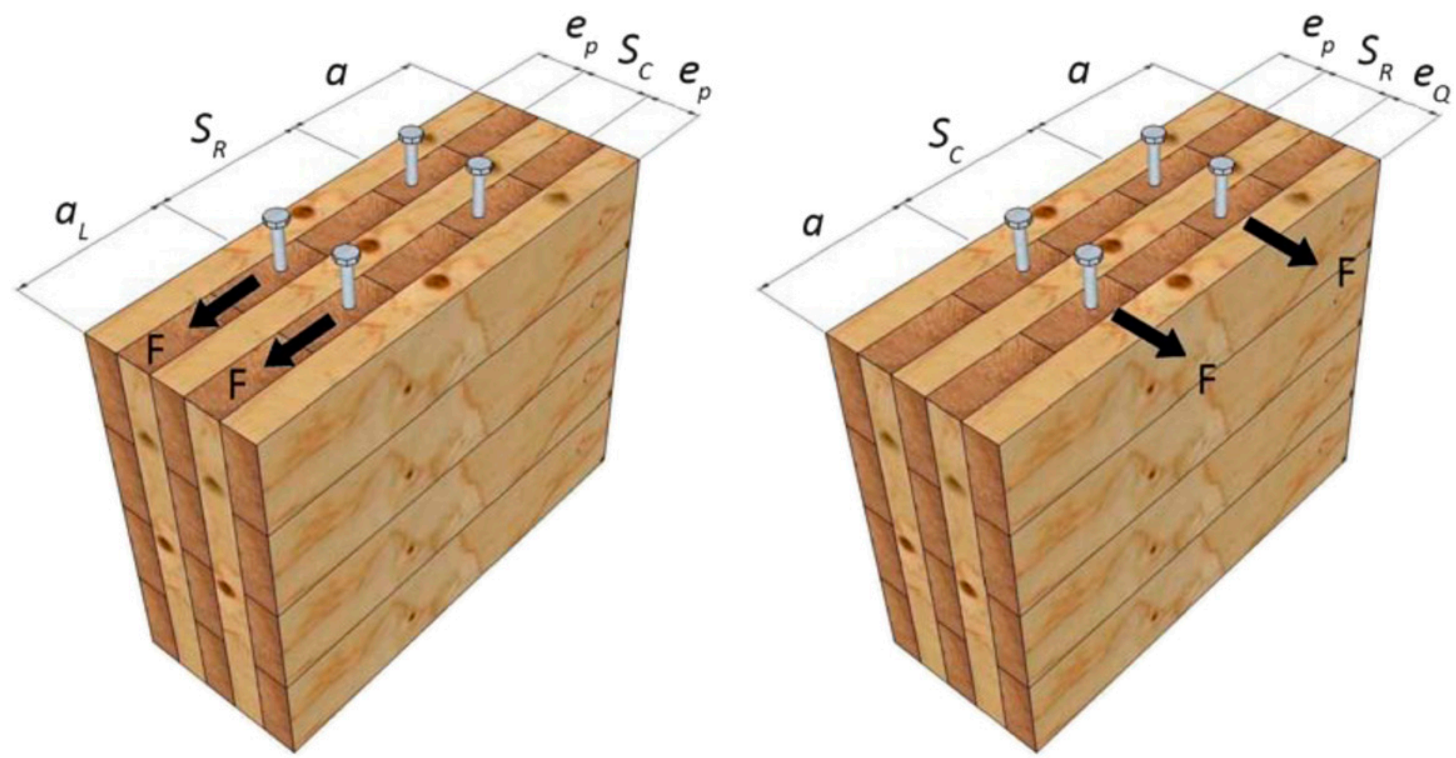

Figure 4. Placement of fasteners in panel edge of cross-laminated timber. 
cross-section and the presence of side and end grain at the panel edges. New NDS criteria for fastener spacing, edge, and end distance address fastener placement in CLT panel edges.

\section{Lateral Resistance of Connections with CLT}

Bolts, dowels, lag screws, nails, spikes, and wood screws. NDS yield mode equations are applicable for the design of dowel type fasteners in CLT panels. Calculation of design lateral capacity follows criteria in the NDS for sawn lumber with additional criteria to address the presence of crossing layers for fasteners installed in the panel face and panel edge.

For dowels with diameter $D>0.250$ inch (typically bolts and lag screws) installed through the panel face, dowel bearing strengths are based on the direction of loading relative to wood grain of the lamination at the shear plane. In addition, where direction of loading at the shear plane is parallel to the grain, the dowel bearing length used in calculation is reduced by multiplying the bearing length of laminations loaded perpendicular to the grain $(\mathrm{Fe} \perp)$ by the ratio of perpendicular to parallel to grain dowel bearing strength (Fell) (i.e., $\mathrm{Fe} \perp / \mathrm{Fe} \|)$. For this case, the adjusted length approach provides exact calibration to the calculated Mode I yield limit state accounting for varying bearing strength over the full length of the dowel. Where the direction of loading at the shear plane is perpendicular to the grain, no adjustment in bearing length is required and it is conservatively assumed that the perpendicular to grain bearing strength is present over the length of the fastener.

Where dowel type fasteners with diameter $D>$ 0.250 inch are installed in the panel edge, the dowel bearing strength is required to be taken as $\mathrm{Fe} \perp$. The required use of $\mathrm{Fe} \perp$ conservatively addresses presence of alternating side grain and end grain in the panel edge. In addition, the calculated reference lateral design value is required to be multiplied by the end grain factor, $C_{\text {eg }}=0.67$, based on the assumption that the fastener is installed in the end grain and in consideration of practical difficulty in ensuring adequate edge distance within individual sawn lumber laminations when installed into the side grain of the panel edge.

For dowels with diameter $D \leq 0.250$ inch (typically nails and wood screws), dowel bearing strength for sawn lumber is the same for loading both parallel and perpendicular to grain and, therefore, no special provision is needed to account for the effect of panel crossing layers. Where the fasteners are installed in the panel edges, adjustment of the calculated reference lateral design value by the end grain factor, $C_{\text {eg }}=0.67$, applies only to fasteners installed in the end grain.

\section{Withdrawal Resistance of Connections in CLT}

NDS withdrawal equations for sawn lumber are generally applicable for fasteners installed through the panel face. New NDS criteria address the alternating presence of side grain and end grain when fasteners are installed in CLT panel edges.

For lag screws installed in the panel edges, the end grain factor, $C_{\mathrm{eg}}=0.75$, adjustment of the calculated reference withdrawal design value is applicable regardless of the actual grain orientation of the installed fastener. Although the $C_{\mathrm{eg}}$ factor is normally applied only to end grain applications in sawn lumber, application to all grain orientations in CLT edges is intended to conservatively account for the mix of end grain and side grain in the narrow face by assuming installation is in the end grain or that minimum edge distance requirements in the side grain of individual sawn lumber laminations are not met. The conservative basis is recognized and possible omission of the 0.75 factor is addressed in the NDS Commentary for cases where installation into the side grain of the panel edge, meeting applicable fastener placement for individual sawn lumber laminations, can be assured.

For wood screws and nails installed in the panel edge, the design withdrawal strength is the same as for sawn lumber. For example, there is no withdrawal value for such fasteners installed in the end-grain (ie end grain factor equal to zero, 
$\left.C_{\text {eg }}=0.0\right)$ and no reduction in withdrawal value when installed in the side grain.

\section{Placement of Fasteners in CLT}

For dowels with diameter $D \geq 0.250$ inch, the NDS includes specific end distance, edge distance, and spacing requirements for fasteners in the CLT panel edge like those for sawn lumber. The new fastener placement provisions are based on overall CLT panel edge dimensions as opposed to being based on individual laminations making up the CLT panel. For smaller diameter, $D<0.250 \mathrm{inch}$, and for fasteners in the panel face, the placement requirements are in accordance with NDS requirements for fasteners in other wood products.

\section{Member Stress at Connections}

Within the NDS, a general clause to check local stresses in connections using multiple fasteners in accordance with principles of engineering mechanics is applicable for wood products including CLT panels. One method to check strength limit states of tension rupture, row tear out, and group tear-out in solid sawn lumber and glued laminated timber wood members is described in the Appendix $\mathrm{E}$ of the NDS.

\section{Other Fasteners}

The design of timber rivets, split rings, and shear plates in CLT panels is beyond the scope of the NDS. Where such fasteners are used, they must be demonstrated by analysis based on recognized theory, full scale or prototype loading tests, studies of model analogues, or extensive experience in use that the design will perform satisfactorily in its intended end use.

\section{CLT CONNECTIONS IN THE NEW ZEALAND TIMBER DESIGN STANDARD}

The New Zealand Building Code cites a series of standards as part of the verification method for design that meets its performance requirements of structural integrity. The verification method for the specific design of timber structures, NZS3603 (NZS3603:1993), does not currently recognize CLT as a structural system. Therefore, the design of CLT structures in New Zealand is considered an alternative solution so that increased design review is required. It will involve the appointment of an independent peer reviewer checking key assumptions and calculations.

In spite of this hurdle, quite a few CLT buildings have been completed. Figure 5 shows a 5-story CLT building currently under construction in Dunedin, New Zealand. There is only one domestic CLT supplier who manufactures CLT panels mainly out of New Zealand grown radiata pine.

In the absence of a design standard, consulting engineers rely on a combination of international literature and guidelines, and manufacturer testing for the design of CLT structures.

New Zealand is a highly seismic country with stringent expectations with regards to seismic design. Connection design, therefore, tends to be governed by the establishment of resistance to lateral loading. In several regions, peak ground accelerations can go higher than $0.3 \mathrm{~g}$ with possible spectral accelerations of $1 \mathrm{~g}$ for short period structures such as 2-3 story CLT buildings (NZS1170.5:2005). To ensure an economically viable structure, engineers often rely on ductility and energy dissipation within the structural system to reduce seismic forces.

\section{The Design of Moment Connections}

Dowel-type connections are also commonly used in CLT design in New Zealand. Bolts, screws and dowels are used to transfer forces between members and to the foundation. Under seismic loading these connections need to reply on inelastic fastener bending and wood crushing to provide energy dissipation. If high levels of ductility are required, failure mechanisms that have dowel bending should be designed for. Crushing only failure may lead to significant connection stiffness degradation or loss where 


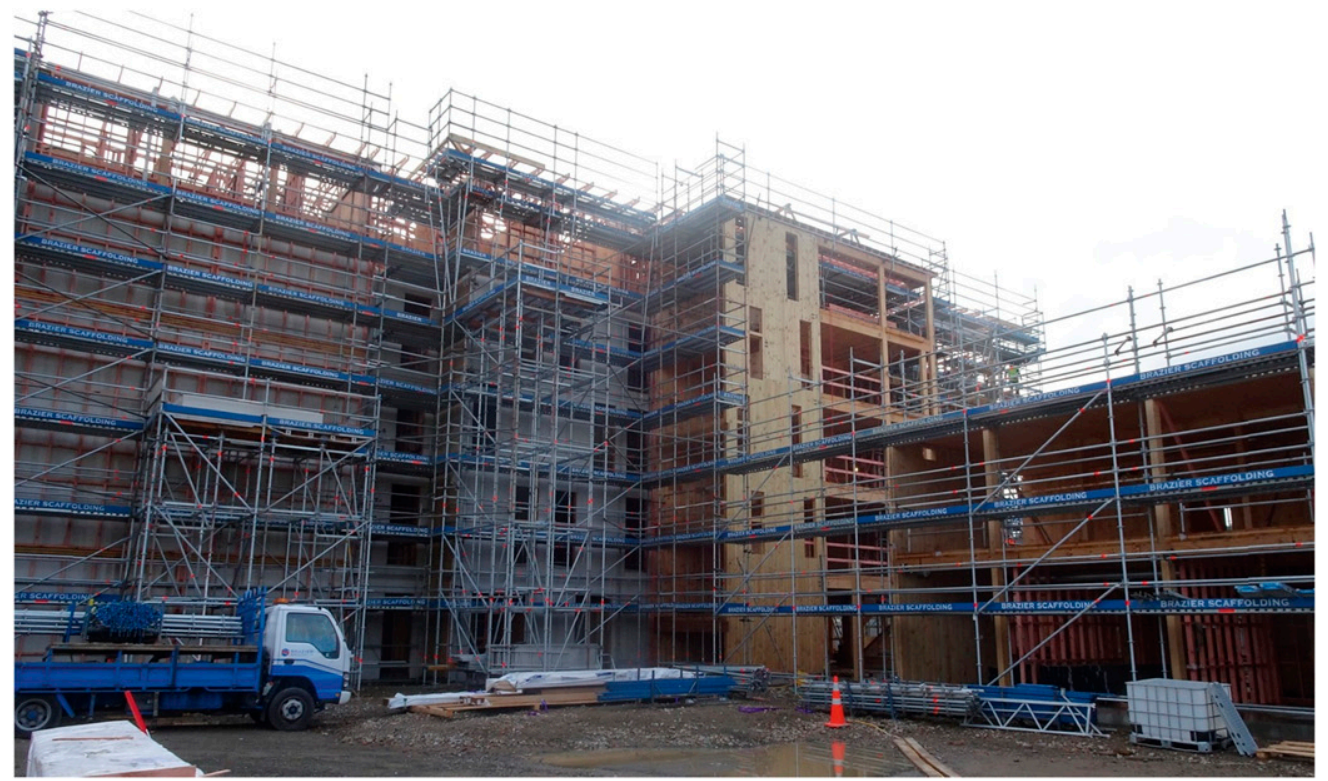

(a)



(b)

Figure 5. Otago polytechnic student village (photos by Sam Leslie). 
a connection will have no resistance in subsequent cycles until the previous maximum displacement demand has been reached. Capacity design approach is also widely used by multiplying connection capacities by probability-based overstrength factors to ensure that nonductile elements remain elastic. Because of the lack of sufficient information on overstrength of CLT connections, engineers tend to use conservative overstrength factors.

As mentioned previously, CLT is not considered within the current New Zealand timber code. Also, it is challenging to predict exactly the type of failure mode for a given CLT connection configuration. For this reason, engineering judgment in combination with international design literature is used when targeting high ductility levels.

Without a standardized method, design considerations can differ between practicing engineers; however, one example of wall lateral design assuming seismic demand in governing is:

1. Calculation of wall lateral demand in accordance with NZS1170.5 assuming a system ductility (eg 3)

2. Single fastener capacity is calculated in accordance with Eurocode 5 (EN 1995-1-1 2004) with embedment strengths from Eurocode 5 and characteristic densities taken from literature for local materials (Franke and Quenneville 2011). When applicable, fastener strengths may be calculated with relevant manufacturer's literature (for example European Technical Approval or New Zealandbased test results). Checks are performed to ensure failure modes include at least one plastic hinge within the fastener when the ductility factors higher than 1.25 are required.

3. Rational analysis is used to ensure brittle failure modes are avoided. Group tear out, for example, is calculated using the net tensile strength of the individual boards. Literature specified fastener spacing are not necessarily relied on to avoid brittle failure (Ottenhaus et al 2016).

4. Maximum building deflections are calculated considering elastic contributions. Elastic contributions may include shear and bending of CLT panels and connection elastic deformations in shear or tension. These are then multiplied by desired ductility levels to check maximum building deformation limits.

The above-mentioned approach is also valid for structures where wind loading is governing the design. However, less stringent check on brittle failure is needed.

\section{The Design of Shear Connections}

Panel-panel and panel-foundation shear connections also represent a critical load path in the lateral load resisting system of the structure. Proprietary shear connections such as long STS from Europe may be used; however, these are often costly when considering the high seismic load demand. In addition, the onsite screwing can add significant onsite time to what would otherwise be a quick installation process. Innovative shear connections through precut castellation (as shown in Fig 5) have also been used; however, this requires additional machining time during the manufacturing process and creates panel wastage.

Recent research results have indicated that the friction between panels is sufficient to resist lateral loading if the vertical force on the interface can be calculated and guaranteed. However, the vertical force from the mass of the structure cannot always be guaranteed, especially in the presence of significant vertical ground accelerations, as observed in the 2011 Canterbury earthquake. The efficient transfer of shear down the building and the understanding of the role of friction still represent a research gap in New Zealand CLT design.

\section{CONCLUSIONS}

This article presents various design approaches for connections in CLT structures developed and adopted in timber design standards worldwide. It is expected that the design procedures will evolve further once the CLT products become more versatile and gain more popularity among 
designers and other stake holders. New generation of CLT and proprietary connection systems facilitating the design and assembly of CLT structures are being developed in Europe, North America, and elsewhere, which could also be adopted in future design standards and serve to the advancement of CLT as a mainstream construction material.

\section{REFERENCES}

Abukari HA, Coté M, Rogers C, Salenikovich A (2012) Withdrawal resistance of structural screws in Canadian glued laminated timber. Proc. WCTE 2012, July 15-19, 2012, Auckland, New Zealand.

AWC, National Design Specifications for Wood Construction (ANSI/AWC NDS-2015), Leesburg (VA): American Wood Council, 2015.

Austrian Standards Institute (ASI) (2015) Eurocode 5: Design of timber structures-Part 1-1: General-Common rules and rules for buildings-National specifications for the implementation of ÖNORM EN 1995-1-1, national comments and national supplements. ÖNORM B 1995-11:2015-06. ASI, Vienna, Austria.

Blaß HJ, Bejtka I, Uibel T (2006) Tragfähigkeit von Verbindungen mit selbstbohrenden Holzschrauben mit Vollgewinde (in German). Number 4 in Karlsruher Berichte zum Ingenieurholzbau. KIT Scientific Publishing, Karlsruhe, Germany.

Blaß HJ, Uibel T (2007) Tragfähigkeit von stiftförmigen Verbindungsmitteln in Brettsperrholz (in German). Number 8 in Karlsruher Berichte zum Ingenieurholzbau. KIT Scientific Publishing, Karlsruhe, Germany.

Brandner R, Flatscher G, Ringhofer A, Schickhofer G, Thiel A (2016) Cross laminated timber (CLT): Overview and development. Eur J Wood Wood Prod 74:331-351.

Canadian Standards Association (CSA) (2014) Engineering design in wood, CSA O86-14, Update \# 1, Toronto, ON, Canada.

European Committee for Standardization (CEN) (2004a) Eurocode 5: Design of timber structures-Part 1-1: General-Common rules and rules for buildings. EN 1995-1-1:2004-11 + AC:2006-06 + A1:2008-06 + A2: 2014-05. CEN, Brussels, Belgium.

European Committee for Standardization (CEN) (2004b) Eurocode 5: Design of timber structures-Part 1-2: General-Structural fire design. EN 1995-1-2:2004-11 + AC:2006-06 + AC:2009-03. CEN, Brussels, Belgium.

European Committee for Standardization (CEN) (2004c) Eurocode 5: Design of timber structures-Part 2: Bridges. EN 1995-2:2004. CEN, Brussels, Belgium.

European Committee for Standardization (CEN) (2016) Structural timber-Strength classes. EN 338-2016-06. CEN, Brussels, Belgium.

European Technical Approval ETA-11/0030 (2012) RothoBlaas self-tapping screws. EOTA.
Franke S, Quenneville P (2011) Bolted and dowelled connections in radiate pine and laminated veneer lumber using the European yield model. Aust J Struct Eng 12(1):13-28.

German Institute for Standardization (DIN) (2013) National annex-Nationally determined parameters-Eurocode 5: Design of timber structures-Part 1-1: General-Common rules and rules for buildings. DIN EN 1995-1-1/NA:201308. DIN, Berlin, Germany.

German National Technical Approval Z-9 1-482 (2015) KLH-Kreuzlagenholz. DIN, Berlin, Germany.

Hübner U (2013) Withdrawal strength of self-tapping screws in hardwoods. International council for research and innovation in building and construction. Working commission W18-Timber Structures. Meeting 46 Vancouver, Canada, August 2013.

Johansen KW (1949) Theory of timber connections. Pages 249-262 in International Association for Bridge and Structural Engineering, Vol. 9.

Kennedy S, Salenikovich A, Munoz W, Mohammad M (2014) Design equations for dowel embedment strength and withdrawal resistance for threaded fasteners in CLT. Proc. WCTE 2014, August 10-14, Quebec City, QC, Canada.

Kennedy S, Salenikovich A, Muñoz W, Mohammad M (2014a) Design equations for dowel embedment strength and withdrawal resistance for threaded fasteners in CLT. In: Proceedings of the World Conference on Timber Engineering 2014, August 10-14, 2014, Québec City, Canada.

Kennedy S, Salenikovich A, Muñoz W, Mohammad M, Sattler D (2014b) Design equations for embedment strength of wood for threaded fasteners in the Canadian timber design code. In: Proceedings of the World Conference on Timber Engineering 2014, August 10-14, 2014, Québec City, Canada.

Kennedy S, Salenikovich A, Muñoz W, Mohammad M (2014c) Design equation for withdrawal resistance of threaded fasteners in the Canadian timber design code. In: Proceedings of the World Conference on Timber Engineering 2014, August 10-14, 2014, Québec City, Canada.

Kleinhenz M, Winter S, Dietsch P (2016) Eurocode 5-A halftime summary of the revision process. Proc. 2016 World Conference on Timber Engineering (WCTE), August 22-25, 2016, Vienna, Austria.

Mohammad M, Quenneville P, Salenikovich A, Zarnani P, Munoz W (2014) Failure modes in CLT connections. Proc. 2014 World Conference on Timber Engineering (WCTE), August 10-14, Quebec City, QC, Canada.

NZS3603:1993 (1993) Timber structures standard. Standards New Zealand, Wellington, New Zealand.

NZS1170.5:2004 (2004) Structural design actions part 5: Earthquake actions-New Zealand. Standards New Zealand, Wellington, New Zealand.

Ottenhaus L-M, Li M, Smith T, Quenneville P (2016) Ductility and overstrength of dowelled LVL and CLT connections under cyclic loading. Proc. 2016 World Conference on Timber Engineering, August 22-25, 2016, Vienna, Austria. 
Pirnbacher G, Schickhofer G (2012) Zeitabhängige Entwicklung der Traglast und des Kriechverhaltens von axial beanspruchten, selbstbohrenden Holzbauschrauben (in German). Research Report. holz.bau forschungs gmbh, Graz, Austria. Ringhofer A, Brandner R, Schickhofer G (2015) Withdrawal resistance of self-tapping screws in unidirectional and orthogonal layered timber products. Mater Struct 48(5): 1435-1447.

Ringhofer A (2017) Axially loaded self-tapping screws in solid timber and laminated timber products. Dissertation. Graz University of Technology, Graz, Austria.

Toratti T (2016) The standardization chain in Europe: MaterialDesign-Execution. Proc. 2016 World Conference on Timber Engineering (WCTE), August 22-25, 2016, Vienna, Austria.
Uibel T, Blaß HJ (2006) Load carrying capacity of joints with dowel type fasteners in solid wood panels. International council for research and innovation in building and construction. Working commission W18-Timber structures. Meeting 39 Florence, Italy, August 2006.

Uibel T, Blaß HJ (2007) Edge joints with dowel type fasteners in cross-laminated timber. International council for research and innovation in building and construction. Working commission W18-Timber structures. Meeting 40 Bled, Slovenia, August 2007.

Uibel T, Blaß HJ (2013) Joints with dowel type fasteners in CLT structures. Pages 119-134 in R Harris, A Ringhofer, and $G$ Schickhofer, eds. Proc. Focus Solid Timber Solutions-European Conference on Cross Laminated Timber, Edition 2, May 21-22, 2013, Graz, Austria. 